\title{
Sphingosine-1-Phosphate Is a Possible Fibrogenic Factor in Gluteal Muscle Fibrosis
}

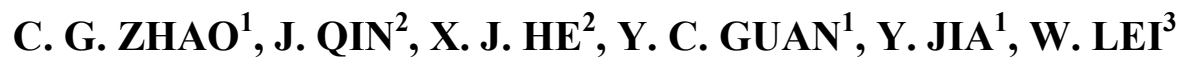 \\ ${ }^{1}$ Orthopedic Center of Chinese PLA, Urumqi General Hospital of Lanzhou Military Region, \\ Urumqi, Xinjiang, China, ${ }^{2}$ Department of Orthopedic Surgery, Second Affiliated Hospital \\ of Medical College, Xi'an JiaoTong University, Xi'an, Shaanxi, China, ${ }^{3}$ Department of Orthopedic \\ Surgery, Xijing Hospital, Fourth Military Medical University, Xi'an, Shaanxi, China
}

Received August 1, 2012

Accepted March 21, 2013

On-line July 17, 2013

\section{Summary}

Gluteal muscle contracture (GMC) is a chronic fibrotic disease of gluteal muscles due to multiple etiologies. The main pathologic process is characterized by proliferation of fibroblasts and excessive accumulation of collagen in the extracellular matrix of the muscle. Sphingosine-1-phosphate (S1P) is a bioactive sphingolipid and has been reported to be associated with various fibrotic diseases. However, the role of S1P in GMC remains unknown. Here in this article, High-performance liquid chromatography and immunohistochemistry were applied to evaluate S1P localization and expression in clinical samples from patients with GMC, Quantitative real time PCR, Western blot, and enzyme-linked immunosorbent assay were used to explore the link between transforming growth factor- $\beta 1$ (TGF- $\beta 1$ ), plasminogen activator inhibitor-1 (PAI-1) and S1P. The results showed that S1P was enhanced in contraction band (CB) tissues. Studies using the cell proliferation and transformation assay indicated that exogenous S1P stimulated $\mathrm{CB}$ fibroblast proliferation in a time-dependent manner and in higher concentration also in a dose-dependent manner. Furthermore, we demonstrated that S1P not only promoted collagen type I production, but also up-regulated mRNA and protein expression of transforming growth factor- $\beta 1$ and plasminogen activator inhibitor-1. These findings suggest that S1P may regulate increased synthesis of collagen and other fibrogenic factors, and significantly contributes to the process of gluteal muscle scarring in patients with GMC.

\section{Key words}

Sphingosine-1-phosphate - S1P • Gluteal muscle contraction • GMC • Fibrosis • TGF- $\beta \bullet$ PAI- 1

\section{Corresponding author}

Chenguang Zhao, Orthopedic Center of Chinese PLA, Urumqi General Hospital of Lanzhou Military Region, 41 Youhao Road, Urumqi 710004, Xinjiang, China.

E-mail: zhao_chenguang@live.cn

\section{Introduction}

Gluteal muscle contracture (GMC) is a chronic fibrotic disease of gluteal muscles resulting from multiple etiologies (Valderrama 1970, Zhao et al. 2009). GMC is characterized by proliferation of fibroblasts and excessive accumulation of collagen in the extracellular matrix (ECM) of muscles (Zhao et al. 2010). During the process, sphingosine-1-phosphate (S1P), which is generated during sphingomyelin metabolism as a pleiotropic lysophospholipid mediator (Donati et al. 2007, Alvarez et al. 2007), stimulates fibroblast proliferation. Under normal physiological conditions, the concentration of $\mathrm{S} 1 \mathrm{P}$ in cells is low and is tightly regulated by the equilibrium between its formation (catalysis by SphK) and degradation (catalyzed by S1P lyase and S1P phosphatase) (Maceyka et al. 2005). S1P is known to be one of the most common fibrotic mediators and has a close relationship with many other fibrotic factors, including transforming growth factor (TGF)- $\beta$, connective tissue growth factor (CTGF), and plateletderived growth factor (PDGF), at the receptor and postreceptor levels (Sauer et al. 2004, Gordon and Blobe 2008).

TGF- $\beta$ s are important members of the TGF 
superfamily and play key roles in cell growth, differentiation, migration, ECM production, and development (Verrecchia and Mauviel 2007). Numerous studies have demonstrated that TGF- $\beta 1$ is expressed at high levels during tissue remodeling, and affects the formation of connective tissue by stimulating the transcription of genes encoding ECM proteins (Liu et al. 2006). Recently, several reports have suggested that TGF- $\beta 1$ 's profibrotic effects may be partially mediated by the S1P pathway (Kono et al. 2007).

Plasminogen activator inhibitor-1 (PAI-1), a member of the serpin superfamily of serine protease inhibitors, is capable of directly degrading matrix components and indirectly inhibiting the deposition of ECM by activating latent matrix metalloproteinases (MMPs). PAI-1 is the major physiologic inhibitor of the plasminogen activator/plasmin protease system and can lead to fibrosis in various organs (Cale and Lawrence 2007). In addition, PAI-1 can be regulated by the S1P pathway (Paugh et al. 2008). Although a fibrogenic role has been documented for S1P during fibrosis in various tissues and organs, the role in muscle fibrosis is not yet known. This study was designed to study the role of S1P in muscle fibrosis in patients with GMC.

\section{Materials and Methods}

\section{Tissue specimens}

Tissue samples (23 contraction bands (CB) and 23 adjacent normal muscle samples) were collected from patients with GMC between January 2007 and March 2008 at the Urumqi General Hospital of Lanzhou Military Region and the Second Affiliated Hospital of Medical College. All procedures involving sample collection were approved by the ethical board of the Urumqi General Hospital of Lanzhou Military Region and the Second Affiliated Hospital of Medical College, and followed the Declaration of Helsinki Guidelines. Informed consent was obtained from all of the involved patients. All 23 patients (10 males and 13 females; age range: 7-27 years) were operated with $\mathrm{CB}$ releasing surgery, as described previously (Zhao et al. 2009).

\section{Cell isolation and culture}

CB fibroblasts isolated from CB tissues of GMC patients were used for in vitro cell culture study. Tissue specimens were cut into blocks of approximately $2 \times 2$ $\mathrm{mm}^{2}$, then washed with distilled water and placed into tissue culture dishes containing DMEM media with fetal calf serum, gentamicin, and amphotericin B (Invitrogen, Carlsbad, CA, USA) for incubation at overnight. Thereafter, DMEM media was changed three times a week. The isolated fibroblasts were subcultured with $0.1 \%$ trypsin and $0.02 \%$ EDTA in $\mathrm{Ca}^{+}$-free minimum essential medium (MEM) at 80-90\% confluence. Only cells past 3-5 generations were used for the further analysis.

Quantitative real-time reverse transcription-PCR ( $q R T$ PCR)

Total RNA was extracted from fibroblasts using TRIzol reagent (Invitrogen). First-strand cDNAs were synthesized by using the RevertAid First Strand cDNA Synthesis Kit (Fermentas, Vilnius, Lithuania) according to the manufacturer's instructions. To quantify mRNA expression of TGF- $\beta 1$ and PAI-1, qRT-PCR using SYBR $^{\circledR}$ Premix Ex Taq $^{\mathrm{TM}}$ II (TaKaRa, Dalian, China) was performed. The gene for $\beta$-actin was amplified as the internal control. Sense and antisense gene-specific primers used in the PCR were:

TGF- $\beta 1$, 5'-CGAGAAGCGGTACCTGAAC-3' and 5'-TGAGGTATCGCCAGGAATTGT-3';

PAI-1, 5'-CGGCTGGTGCTGGTGAATG-3' and 5'-CATCGGGCGTGGTGAACTC-3'; $\beta$-actin, 5'-ATCGTGCGTGACATTAAGGAGAAG-3' and 5'-CATCGGGCGTGGTGAACTC-3'.

Real-time measurements of gene expression were performed with the $\mathrm{iQ5}^{\mathrm{TM}}$ Multicolor Real-Time PCR and Detection System (Bio-Rad, Hercules, CA, USA). Relative mRNA levels were calculated by the $2^{-\Delta \Delta \mathrm{CT}}$ method. Quantitative real-time PCR experiments were repeated in triplicate.

\section{Immunohistochemistry}

Immunohistochemistry was performed on paraffin sections, as described previously (Zhao et al. 2010). Briefly, paraffin sections were deparaffinized, then soaked in $0.3 \%$ hydrogen peroxide in methanol to inactivate endogenous peroxidase activity. After mild treatment with $0.05 \%$ trypsin-EDTA, the sections were incubated with $10 \%$ goat serum to block non-specific protein binding. The blocked sections were incubated with antibodies against S1P (1:600; Lpath, San Diego, CA, USA), or antibodies against TGF- $\beta 1$ and PAI-1 (both 1:300; Santa Cruz Biotechnology, Santa Cruz, CA, USA) at $4{ }^{\circ} \mathrm{C}$ overnight. After incubation with the primary antibodies, the sections were incubated with secondary antibody and alkaline phosphatase streptavidin (Vector 
Laboratories, Burlingame, CA, USA). The sections were then stained using the Vector Red Alkaline Phosphatase Substrate Kit (Vector Laboratories), according to the manufacturer's instructions, and counterstained with Mayer's hematoxylin. One section from each series was incubated with phosphate buffered saline (PBS) in lieu of the first antibody for use as a negative control. The staining intensities were graded semi-quantitatively using the following scale: $(-)$, no staining; $(+)$, weak staining; $(++)$, moderate staining; and $(+++)$, strong staining.

\section{Western blotting}

Crude proteins were extracted from S1P-treated fibroblasts, and protein concentrations were quantified using the BCA Protein Assay (Pierce, Rockford, IL, USA). Equivalent amounts of proteins $(20 \mu \mathrm{g})$ were fractionized by SDS-PAGE and subsequently transferred to polyvinylidene difluoride (PVDF) membranes (BioRad). The membranes were then blocked with $10 \%$ fatfree skim milk powder in PBS containing $0.1 \%$ Tween 20 (PBST), and incubated with antibodies against TGF$\beta 1$ or PAI-1 (both 1:200). After a series of brief PBST washes, the membranes were incubated with the appropriate species-specific horseradish peroxidaseconjugated antibodies (1:5000; Jackson ImmunoResearch, West Grove, PA, USA). Antibodyspecific bands were visualized using standard ECL chemiluminescence reagents (Pierce) and photographed. The density of each band was measured by densitometry. The relative expression of $\alpha$-SMA, TGF- $\beta 1$ and PAI- 1 proteins were normalized to the expression of the internal control ( $\beta$-actin).

\section{High-performance liquid chromatography (HPLC) analysis}

Extraction of S1P from tissues was carried out as described previously (Min et al. 2002). Briefly, tissue samples were homogenized and ultrasonicated in ice-cold water. Methanol was added and the samples were ultrasonicated for an additional $10 \mathrm{~min}$ in ice-cold water. Lipids were extracted by adding $500 \mu \mathrm{l}$ of $\mathrm{CHCl}_{3} / 1 \mathrm{M}$ $\mathrm{NaCl}(1: 1 \mathrm{v} / \mathrm{v})$ and $25 \mu \mathrm{l}$ of $3 \mathrm{M} \mathrm{NaOH}$. The basic aqueous phase was transferred to a siliconized glass tube and all of the aqueous fractions were combined. The aqueous phase containing S1P was mixed with $150 \mu$ of buffer and 50 units of alkaline phosphatase (Sigma, St. Louis, MO, USA). The mixture was incubated at $37{ }^{\circ} \mathrm{C}$ for $45 \mathrm{~min}$ and terminated by addition of $\mathrm{HCl}$. The pooled $\mathrm{CHCl}_{3}$ phase was washed three times with alkaline water and then dried under nitrogen in siliconized glass tubes. The dried lipid residue was resuspended in $200 \mu \mathrm{l}$ of ethanol for $30 \mathrm{~min}$. The dissolved lipid solution was incubated for $1 \mathrm{~h}$ at room temperature. Sample analysis was carried out with an Agilent 1100 HPLC instrument (Santa Clara, CA, USA). The derivatives were detected using a spectrofluorometer, with an excitation wavelength of $340 \mathrm{~nm}$ and an emission wavelength of $455 \mathrm{~nm}$.

\section{Cell proliferation}

CB fibroblast cells were plated on 96-well plates at a density of $5 \times 10^{3}$ cells/well. Plated cells were synchronized overnight in serum-free media and then treated with varying concentrations of S1P for 24,48 or $72 \mathrm{~h}$. Cell proliferation was examined using a cell proliferation assay kit (Invitrogen), according to the manufacturer's instructions. Absorbance was measured at $\mathrm{OD}_{450}$ and data were expressed as the fold-change relative to control. Absorbance measurements were performed independently three times.

Measurement of procollagen type I C-peptide with enzyme-linked immunosorbent assay (ELISA)

Procollagen type I C-peptide (PICP) concentrations were determined by ELISA. Briefly, fibroblasts were plated overnight in culture media at a density of $1 \times 10^{5}$ cells/well on 12 -well dishes. Plated cells were synchronized overnight in serum-free media and then treated with varying concentrations of S1P. After media isolation, collagen type I production was measured using a PICP ELISA kit (TaKaRa), according to the manufacturer's instructions. The expression of PICP was normalized for the amount of cellular protein in each well.

\section{Statistical analysis}

All values were expressed as the mean \pm SEM. The paired T-test and one-way ANOVA test were used to examine differences between groups. All statistical analyses were performed using SPSS 13.0 software. $P$-values $<0.05$ were considered significant.

\section{Results}

\section{S1P level is increased in contraction band tissues}

Initially, we performed immunohistochemistry to determine the localization and level of S1P in $\mathrm{CB}$ and adjacent muscles. The results showed that $\mathrm{CB}$ fibroblasts 
contained prominent pools of S1P. The S1P level was remarkably high in fibroblasts $(+++$; arrowhead) and vascular endothelial cells $(+++$; arrow) in contraction bands (Fig. 1A). In contrast, S1P was weakly and sparsely detected in vascular endothelial cells in adjacent muscle sections (+; Fig. 1B). This pattern of S1P level was further confirmed by HPLC analysis, which showed that S1P was significantly enriched in contraction bands, as compared to that in adjacent normal muscle (Fig. 1E).
A

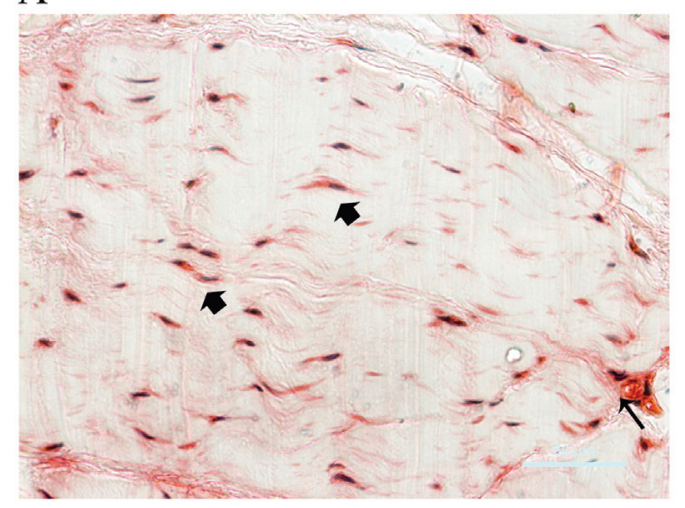

C

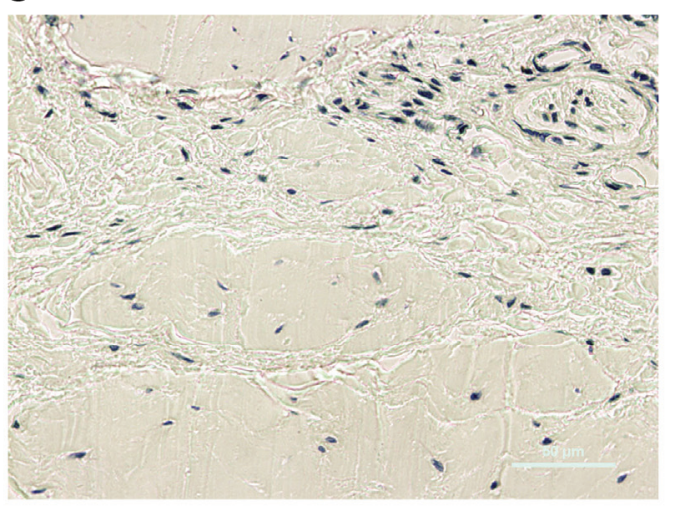

E
B

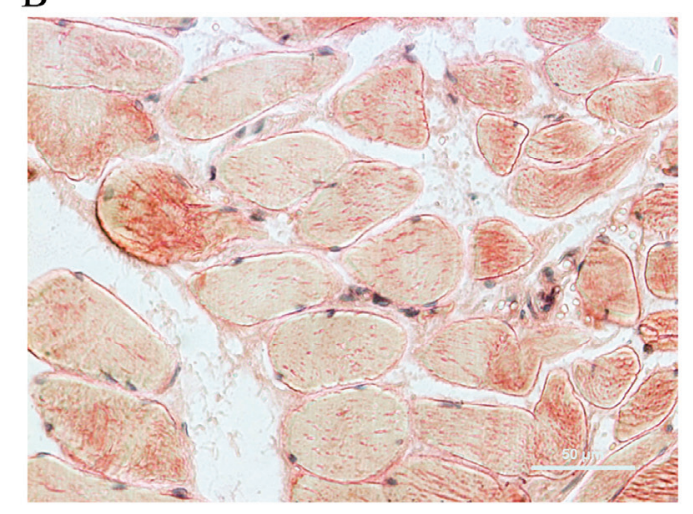

D

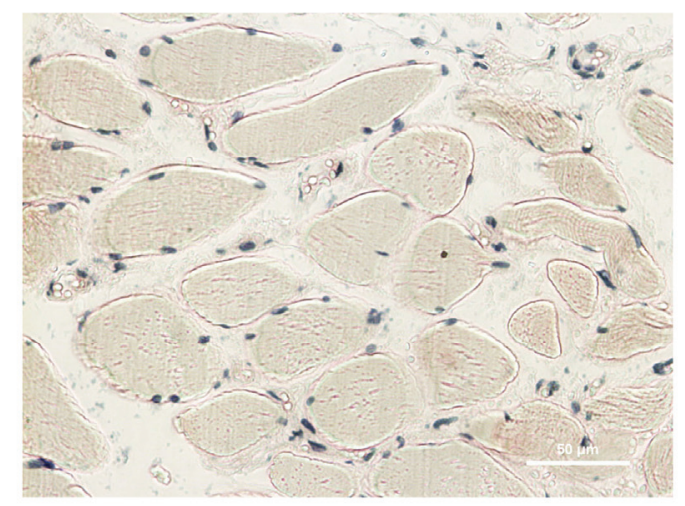

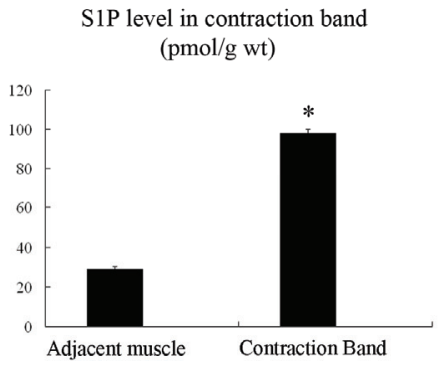

Fig. 1. Immunohistochemical and HPLC analyses for S1P in contraction bands and unaffected adjacent muscles. Staining was carried out with antibodies against S1P (A, B), or without a primary antibody (control) $(\mathbf{C}, \mathbf{D})$ in contraction bands $(\mathbf{A}, \mathbf{C})$ and unaffected adjacent muscles (B, D). S1P that was specifically recognized by the antibodies stained red, whereas nuclei were counter-stained blue. Positive cells were fibroblasts and vascular endothelial cells. Scale bars: $50 \mu \mathrm{m}$ (A-D). (E) S1P level was measured by HPLC. The results showed the SIP level in contraction bands compared with adjacent muscles in 23 GMC patients.

\section{S1P stimulates proliferation of CB fibroblasts}

The high level of S1P in CB of fibrotic muscle suggests its pathophysiological role in fibroblast. To address this, CB fibroblasts were treated with various concentrations of S1P for 24,48 or $72 \mathrm{~h}$ to investigate the effect of S1P on proliferation of CB fibroblasts. As shown in Figure 2, upon S1P treatment, $\mathrm{CB}$ fibroblasts exhibited a time-dependent increase in basal cell proliferation $(0 \mu \mathrm{M}$ $\mathrm{S} 1 \mathrm{P}$ ) and a time-dependent progressive increase at all different treatment levels. In addition, CB fibroblasts showed a dose-dependent increase in S1P-mediated cell proliferation at all time points examined (Fig. 2). Altogether, these results imply that S1P may regulate the proliferation of $\mathrm{CB}$ fibroblasts.). 


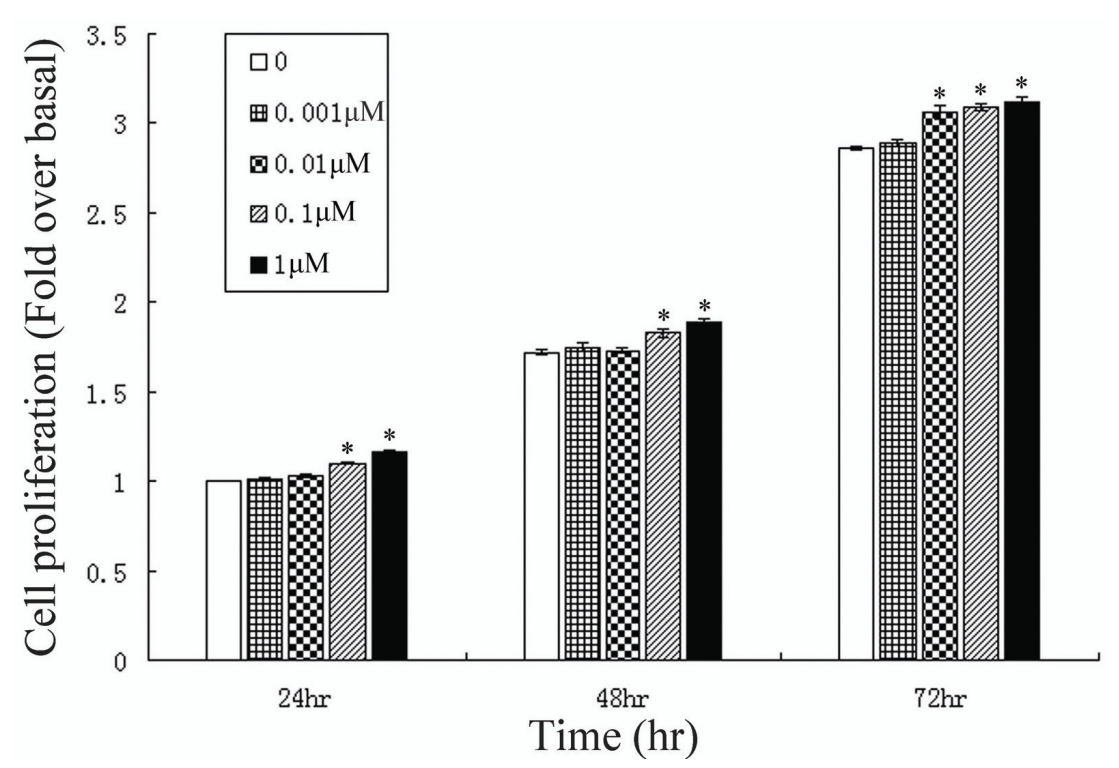

Fig. 2. $S 1 P$ stimulates proliferation of $C B$ fibroblasts of GMC patients. $5 \times 10^{3}$ plated cells were synchronized overnight in serum-free media, and treated with varying concentrations of S1P for 24,48 or 72 h. Note that S1P stimulated CB fibroblast proliferation was with timedependent manner and upon higher concentration treatment, CB fibroblast proliferation was also with dose-dependent manner. Data were expressed as the fold change relative to control ( $0 \mathrm{mM} \mathrm{S1P})$ at the $24 \mathrm{~h}$ time point. Absorbance measurements were performed independently three times.
A

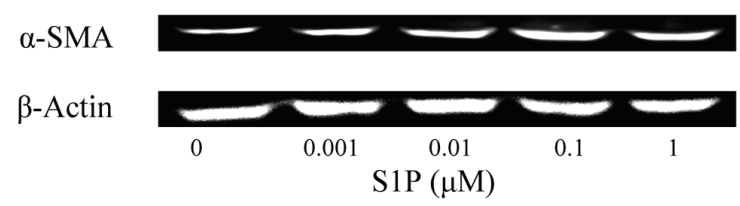

B

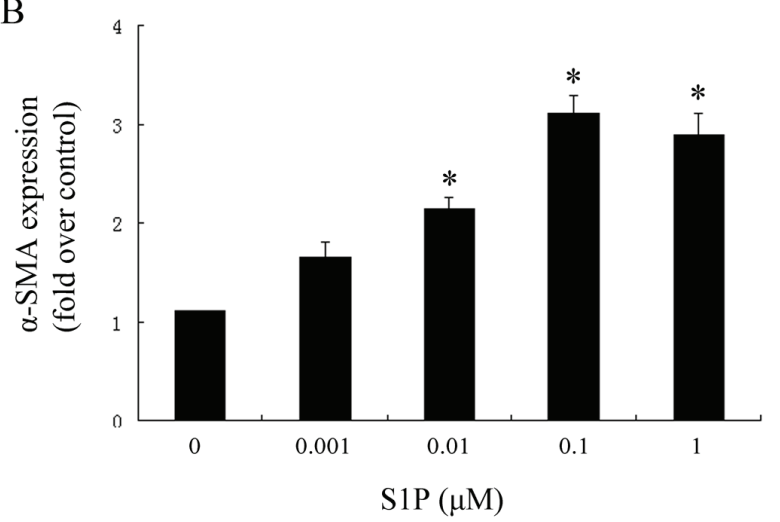

C

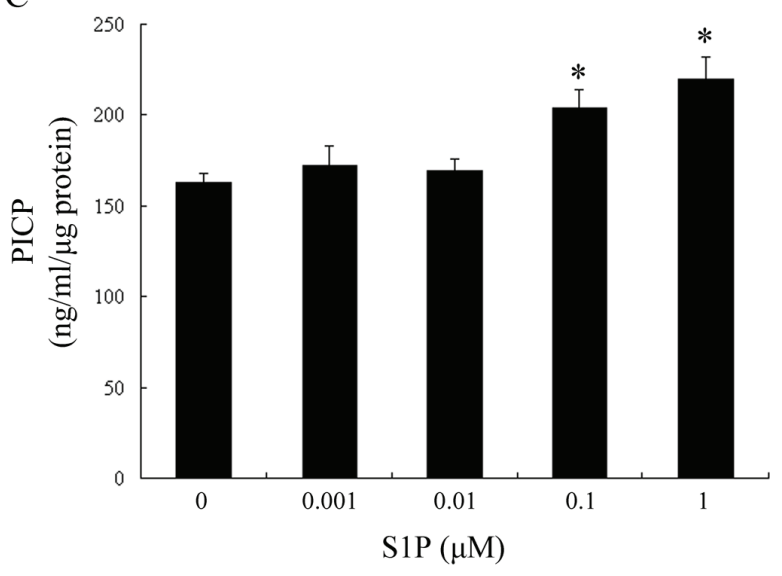

Fig. 3. S1P stimulates a-SMA expression and procollagen type I C-peptide I production by $C B$ fibroblasts of $G M C$ patients. (A) Western blot analysis of a-SMA expression by CB fibroblasts that were serum-starved for $24 \mathrm{~h}$ and then treated with different concentrations of S1P. (B) Densitometry of protein levels of aSMA (fold-change). (C) PICP concentrations were determined by ELISA in supernatants of fibroblasts that were serum-starved for $24 \mathrm{~h}$ and then treated with varying concentrations of S1P. Values in each experiment represent the mean \pm SEM of three independent experiments.

SIP induces collagen type I production by CB fibroblasts Because previous studies have shown that S1P could promote epithelial-to-mesenchymal transition (EMT), we hypothesized that S1P could promote $\alpha$ smooth muscle actin (SMA) expression, which is a marker of myofibroblasts, and collagen type I production by CB fibroblasts. As shown in Figure 3, S1P stimulated the expression of $\alpha$-SMA in a dose-dependent manner, with an approximate 3 -fold increase at the highest dose tested (Fig. 3A, B). Likewise, S1P also promoted type I collagen production by CB fibroblasts. Stimulation with increasing levels of S1P (0.001-1 $\mu \mathrm{M})$ resulted in dosedependent increases in collagen type I expression, with a 1.4-fold increase in type I collagen expression at the highest dose tested (Fig. 3C).

$S 1 P$ increases pro-fibrotic protein expression by $C B$ fibroblasts

Since TGF- $\beta 1$ has the potential to mediate muscle fibrosis and PAI-1 is linked with decreases in collagen proteolytic degradation, we examined the effects of S1P on the expression of TGF- $\beta 1$ and PAI- 1 . Using qRT-PCR, we evaluated the mRNA levels of TGF- $\beta 1$ and PAI-1 induced by S1P. As shown in Figure $4 \mathrm{~A}$ and $4 \mathrm{~B}, \mathrm{~S} 1 \mathrm{P}$ induced a 
dose-dependent increase in mRNA expression of TGF- $\beta 1$ and PAI-1. Next, immunohistochemical staining showed that, compared with control non-treated CB fibroblasts, S1P-treated fibroblasts showed enhanced cytoplasmic expression of TGF- $\beta 1$ and PAI-1 (Fig. 4C-F). In parallel, Western blot analysis revealed that the expression of total protein for both TGF- $\beta 1$ and PAI-1 was increased in S1Ptreated fibroblasts. $\mathrm{S} 1 \mathrm{P}$ treatment of $\mathrm{CB}$ fibroblasts resulted in the induction of TGF- $\beta 1$ (as high as 1.75 -fold) and PAI-1 (as high as 5-fold) (Fig. 4G-J). Collectively, these results suggest that $\mathrm{S} 1 \mathrm{P}$ is capable of inducing expression of TGF- $\beta 1$ and PAI-1 in CB fibroblasts.
A

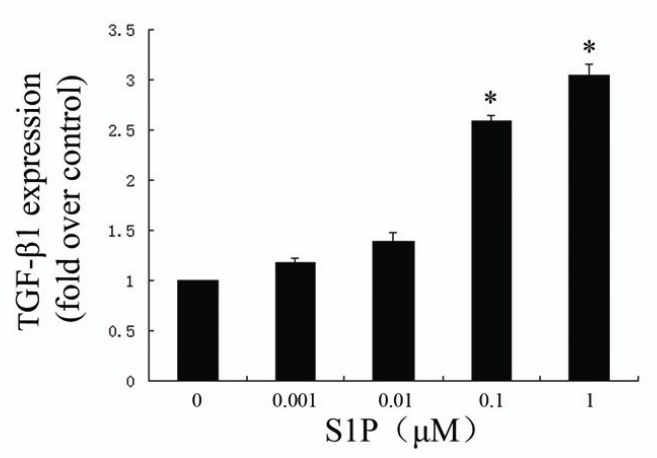

C

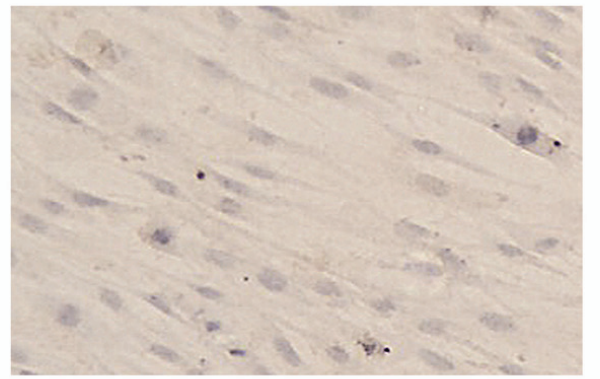

E

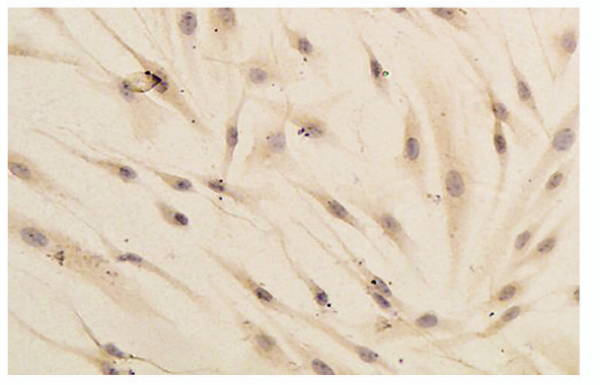

$\mathrm{G}$

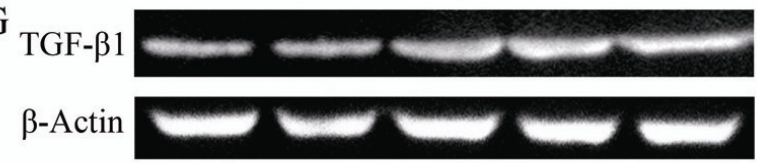

\section{I}

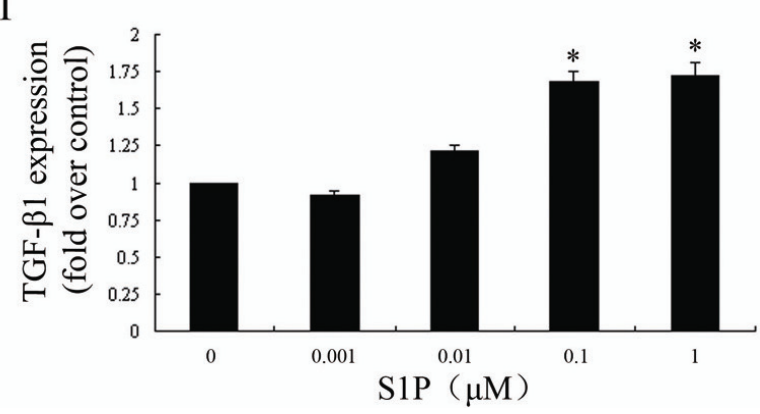

B

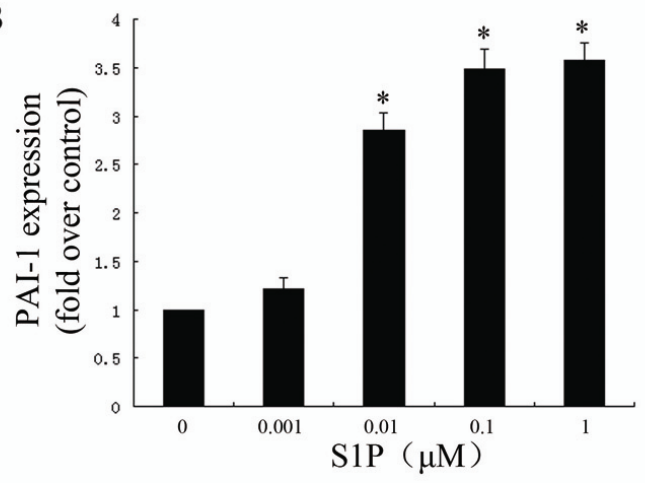

D

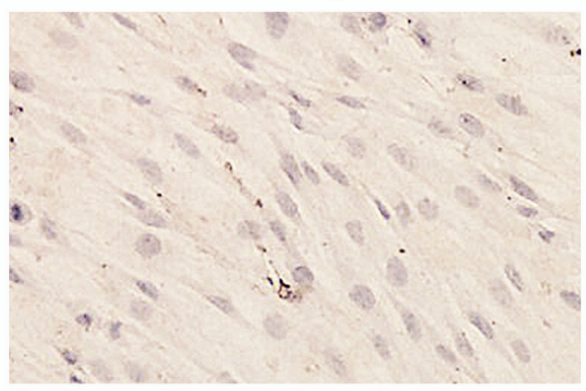

F

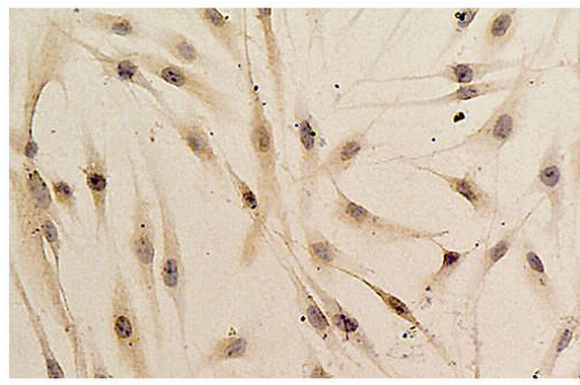

$\mathrm{H}$
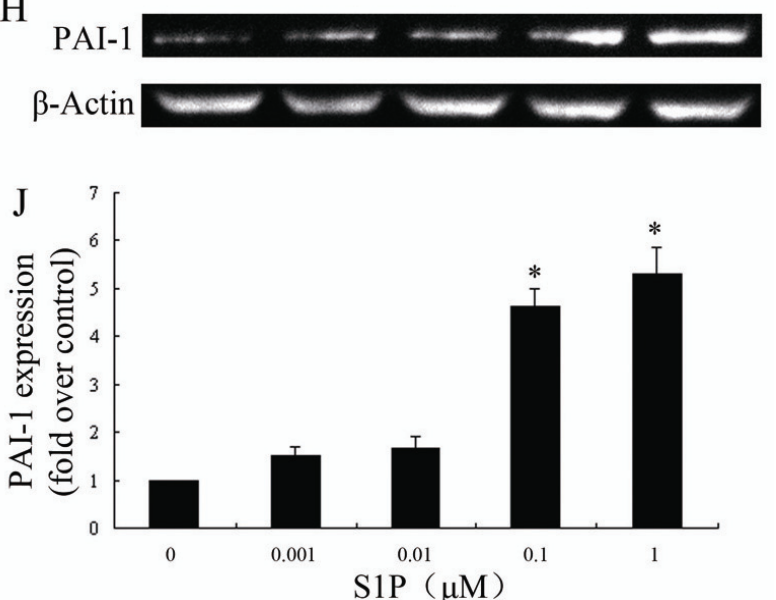

Fig. 4. S1P stimulated TGF- $\beta 1$ and PAI- 1 expression by CB fibroblasts of GMC patients. (A, B) Relative expression of TGF- $\beta 1$ and PAI- 1 of mRNA levels after treating with different concentrations of S1P (fold-change) were evaluated by qRT-PCR analysis. Increased cytoplasmic staining with antibodies against TGF- $\beta 1$ (E) and PAI-1 (F) was noted in the S1P-treated CB fibroblasts of GMC patients; as compared to the control group (C, D). Expression of TGF- $\beta 1$, PAI-1, and $\beta$-actin in CB fibroblasts of GMC patients were examined by Western blot analysis $(\mathbf{G}, \mathbf{H})$. Data were normalized to $\beta$-actin expression and presented as a fold-change $(\mathbf{I}, \mathbf{J})$. 


\section{Discussion}

In the current study, we have shown a possible role for $\mathrm{S} 1 \mathrm{P}$ in the pathogenesis of chronic muscle fibrosis in patients with GMC. Our results indicate that the level of S1P was up-regulated in muscle fibrosis. Exogenous S1P stimulated CB fibroblast proliferation in a dose- and time-dependent manner, and promoted $\alpha$ SMA expression and collagen type I production. Furthermore, S1P also induced expression of TGF- $\beta 1$ and PAI-1 at both the mRNA and protein levels. These studies revealed that $\mathrm{S} 1 \mathrm{P}$ is a multifunctional mediator associated with muscle fibrogenesis.

S1P is a small, extracellular, sphingolipid signaling growth factor with pleiotropic actions mediated by a complement of five high-affinity $\mathrm{G}$ protein-coupled receptors specific for the ligand (Takuwa et al. 2001). S1P has recently been characterized as a regulator of a variety of critical cellular events, such as proliferation, migration, survival, cytoskeletal organization, adherens junction assembly, and immune function (Ikeda et al. 2009, Katsuma et al. 2005). Although numerous studies have demonstrated that $\mathrm{S} 1 \mathrm{P}$ is an important mediator in tissue fibrosis (Li et al. 2009a), we demonstrated, for the first time, that S1P can act as a muscle fibrotic factor in the GMC process.

The current study showed a strong positive staining for S1P in fibroblasts and vascular endothelial cells of fibrotic lesions from GMC patients, but weak and sparse staining in adjacent muscle sections. Previous studies have shown that extracellular S1P regulates a variety of cellular events via activation of five $\mathrm{G}$ proteincoupled receptors (Takuwa et al. 2001), but the exact source of S1P remains unclear. Our findings directly demonstrate the S1P pool in fibroblasts and vascular endothelial cells, suggesting that S1P may act in a paracrine or autocrine manner to activate receptors, having subsequent effects on cell function, including fibrosis. Moreover, our results revealed the up-regulated level of S1P in biopsies of GMC patients, and upregulation of S1P was accompanied by an increased expression and deposition of collagens, as demonstrated previously (Zhao et al. 2010). Accordingly, it is very likely that the increased level of S1P may in turn increase the synthesis of collagens, leading to muscle fibrosis in GMC patients.

In keeping with our hypothesis that S1P can upregulate the synthesis of collagens and facilitate muscle fibrosis, we next examined the impacts of $\mathrm{S} 1 \mathrm{P}$ on $\mathrm{CB}$ fibroblasts. We found that exogenous S1P stimulated CB fibroblast proliferation in a dose- and time-dependent manner. Moreover, exogenous S1P could directly stimulate the expression of $\alpha$-SMA, a marker of myofibroblasts, and synthesis of collagen type I, the main component of ECM. These findings suggest that, with the stimulation of S1P, CB fibroblasts were promoted to transform to myofibroblast-like cells, and to produce increased ECM. Similar results were obtained for other pro-fibrotic factors, including TGF- $\beta$, CTGF, and PDGF. Consistent with these findings, several previous studies have documented an increased expression of $\alpha$-SMA and accumulation of collagens in human and experimental models of fibrosis (Ikeda et al. 2009, Li et al. 2009b).

Various pro-fibrotic factors, such as TGF- $\beta 1$, TGF- $\beta 2$, CTGF and PDGF, have the potential to mediate fibrogenesis in humans and experimental animals. Among these pro-fibrotic factors, TGF- $\beta 1$ has been the most frequently studied (Ask et al. 2008). TGF- $\beta 1$ has been shown to be up-regulated during tissue repair, leading to fibrosis by increasing the accumulation of collagen in the ECM of muscle (Razzaque et al. 2003, Waters et al. 2003). Here, we showed that S1P exhibited features of cross-talk with TGF- $\beta 1$. In particular, S1P induced a dose-dependent increase at the mRNA and protein levels of TGF- $\beta 1$, which is consistent with a related report (Hobson et al. 2001). Taken together, the direct effects of S1P on fibrogenesis and the indirect effects of S1P in promoting TGF- $\beta 1$-mediated fibrosis suggest that S1P has an important role in muscle fibrosis.

Fibrotic diseases involve not only increased production of collagen, but also an abnormal molecular process leading to collagen degradation. PAI-1 is the major physiologic inhibitor of the plasmin protease system. Plasmin is the primary effective enzyme in fibrinolysis and participates in the breakdown of ECM proteins (Lambert et al. 2001). In the presence of PAI-1, normal matrix synthesis would be expected to yield higher levels of matrix because of the lack of plasmin activity and the attendant matrix turnover. Thus, we hypothesize that the ability of S1P to promote muscle fibrosis may involve its capacity to stimulate collagen production, as well as its ability to inhibit collagen degradation. Consistent with this hypothesis, we found that S1P up-regulated the expression of PAI-1 at the mRNA and protein levels. This two-way ability of S1P makes S1P an even more important mediator in the process of gluteal muscle scarring in patients with GMC. 


\section{Conclusion}

The present study demonstrated that the expression level of S1P was increased in conjunction with excessive accumulation of collagens in specimens obtained from patients with GMC. Consistent with this phenomenon, S1P was shown to stimulate proliferation, $\alpha$-SMA expression, collagen type I production, and expression of TGF- $\beta 1$ and PAI- 1 by CB fibroblasts. S1P may regulate increased synthesis of collagens and other fibrogenic factors, and thereby can significantly contribute to the process of gluteal muscle scarring in patients with GMC. All of these findings provide important insights into the molecular mechanism underlying GMC and could provide specific sites for molecular therapeutic intervention to prevent or arrest progression of this disease.

\section{Conflict of Interest}

There is no conflict of interest.

\section{Acknowledgements}

This study was supported by a grant from the Food and Drug Administration of Shaanxi Province (Y200 334002).

\section{References}

ALVAREZ SE, MILSTIEN S, SPIEGEL S: Autocrine and paracrine roles of sphingosine-1-phosphate. Trends Endocrinol Metab 18: 300-307, 2007.

ASK K, BONNIAUD P, MAASS K, EICKELBERG O, MARGETTS PJ, WARBURTON D, GROFFEN J, GAULDIE J, KOLB M: Progressive pulmonary fibrosis is mediated by TGF-beta isoform 1 but not TGF-beta3. Int $J$ Biochem Cell Biol 40: 484-495, 2008.

CALE JM, LAWRENCE DA: Structure-function relationships of plasminogen activator inhibitor-1 and its potential as a therapeutic agent. Curr Drug Targets 8: 971-981, 2007.

DONATI C, CENCETTI F, NINCHERI P, BERNACCHIONI C, BRUNELLI S, CLEMENTI E, COSSU G, BRUNI P: Sphingosine 1-phosphate mediates proliferation and survival of mesoangioblasts. Stem Cells 25: 1713-1719, 2007.

GORDON KJ, BLOBE GC: Role of transforming growth factor-b superfamily signaling pathways in human disease. Biochim Biophys Acta 1782: 197-228, 2008.

HOBSON JP, ROSENFELDT HM, BARAK LS, OLIVERA A, POULTON S, CARON MG, MILSTIEN S, SPIEGEL S: Role of the sphingosine-1-phosphate receptor EDG-1 in PDGF-induced cell motility. Science 291: 1800-1803, 2001.

IKEDA H, WATANABE N, ISHII I, SHIMOSAWA T, KUME Y, TOMIYA T, INOUE Y, NISHIKAWA T, OHTOMO N, TANOUE Y, IITSUKA S, FUJITA R, OMATA M, CHUN J, YATOMI Y: Sphingosine 1phosphate regulates regeneration and fibrosis after liver injury via sphingosine 1-phosphate receptor 2. J Lipid Res 50: 556-564, 2009.

KATSUMA S, RUIKE Y, YANO T, KIMURA M, HIRASAWA A, TSUJIMOTO G: Transcriptional regulation of connective tissue growth factor by sphingosine 1-phosphate in rat cultured mesangial cells. FEBS Lett 579: 2576-2582, 2005.

KONO Y, NISHIUMA T, NISHIMURA Y, KOTANI Y, OKADA T, NAKAMURA S, YOKOYAMA M: Sphingosine kinase 1 regulates differentiation of human and mouse lung fibroblasts mediated by TGF-beta 1. Am J Respir Cell Mol Biol 37: 395-404, 2007.

LAMBERT V, MUNAUT C, NOËL A, FRANKENNE F, BAJOU K, GERARD R, CARMELIET P, DEFRESNE MP, FOIDART JM, RAKIC JM: Influence of plasminogen activator inhibitor type 1 on choroidal neovascularization. FASEB J 15: 1021-1027, 2001.

LI C, JIANG X, YANG L, LIU X, YUE S, LI L: Involvement of sphingosine 1-phosphate (SIP)/S1P(3) signaling in cholestasis-induced liver fibrosis. Am J Pathol 175: 1464-1472, 2009a.

LI C, KONG Y, WANG H, WANG S, YU H, LIU X, YANG L, JIANG X, LI L, LI L: Homing of bone marrow mesenchymal stem cells mediated by sphingosine 1-phosphate contributes to liver fibrosis. J Hepatol 50: 1174$1183,2009 b$. 
LIU X, HU H, YIN QJ: Therapeutic strategies against TGF-b signaling pathway in hepatic fibrosis. Liver Int 26: 8-22, 2006.

MACEYKA M, SANKALA H, HAIT NC, LE STUNFF H, LIU H, TOMAN R, COLLIER C, ZHANG M, SATIN LS, MERRILL AH, MILSTIEN S, SPIEGEL S: SphK1 and SphK2, sphingosine kinase isoenzymes with opposing functions in sphingolipid metabolism. $J$ Biol Chem 280: 37118-37129, 2005.

MIN JK, YOO HS, LEE EY, LEE WJ, LEE YM: Simultaneous quantitative analysis of sphingoid base 1-phosphates in biological samples by o-phthalaldehyde precolumn derivatization after dephosphorylation with alkaline phosphatasel. Anal Biochem 303: 167-175, 2002.

PAUGH BS, PAUGH SW, BRYAN L, KAPITONOV D, WILCZYNSKA KM, GOPALAN SM, ROKITA H, MILSTIEN S, SPIEGEL S, KORDULA T: EGF regulates plasminogen activator inhibitor-1 (PAI-1) by a pathway involving c-Src, PKC , and sphingosine kinase 1 in glioblastoma cells. FASEB J 22: 455-465, 2008.

RAZZAQUE MS, FOSTER CS, AHMED AR: Role of collagen-binding heat shock protein 47 and transforming growth factor-beta1 in conjunctival scarring in ocular cicatricial pemphigoid. Invest Ophthalmol Vis Sci 44: 1616$1621,2003$.

SAUER B, VOGLER R, VON WENCKSTERN H, FUJII M, ANZANO MB, GLICK AB, SCHÄFER-KORTING M, ROBERTS AB, KLEUSER B: Involvement of Smad signaling in sphingosine 1-phosphate-mediated biological responses of keratinocytes. $J$ Biol Chem 279: 38471-38479, 2004.

TAKUWA Y, OKAMOTO H, TAKUWA N, GONDA K, SUGIMOTO N, SAKURADA S: Subtype-specific, differential activities of the EDG family receptors for sphingosine-1-phosphate, a novel lysophospholipid mediator. Mol Cell Endocrinol 177: 3-11, 2001.

VALDERRAMA JAF: A cause of limited flexion and adduction of the hip in children. J Bone Joint Surg 52: 179, 1970.

VERRECCHIA F, MAUVIEL A: Transforming growth factor-beta and fibrosis. World J Gastroenterol 13: 3056-3062, 2007.

WATERS C, SAMBI B, KONG KC, THOMPSON D, PITSON SM, PYNE S, PYNE NJ: Sphingosine 1-phosphate and platelet-derived growth factor (PDGF) act via PDGF beta receptor-sphingosine 1-phosphate receptor complexes in airway smooth muscle cells. J Biol Chem 278: 6282-6290, 2003.

ZHAO CG, HE XJ, LU B, LI HP, WANG D, ZHU ZZ: Classification of gluteal muscle contracture in children and outcome of different treatments. BMC Musculoskelet Disord 10: 34, 2009.

ZHAO CG, HE XJ, LU B, LI HP, KANG AJ: Increased expression of collagens, transforming growth factor- $\beta 1$, and $-\beta 3$ in gluteal muscle contracture. BMC Musculoskelet Disord 11: 15, 2010. 